\title{
Gender pay gap perception: a five-country European study
}

\author{
Giulia Lausi $^{1}$ (D) Jessica Burrai ${ }^{1,2}$ - Benedetta Barchielli ${ }^{2}$. \\ Alessandro Quaglieri ${ }^{1}$ (D) Emanuela Mari ${ }^{1}$ (D) . Angelo Fraschetti ${ }^{1}$ (D) \\ Fabrizio Paloni $^{1} \cdot$ Pierluigi Cordellieri $^{1}$ (D) Fabio Ferlazzo ${ }^{1}$ (D) \\ Anna Maria Giannini ${ }^{1}$ (iD
}

Received: 24 November 2020 / Accepted: 7 October 2021

(c) The Author(s), under exclusive licence to Springer Nature Switzerland AG 2021

\begin{abstract}
Over the past several decades, public administrations have attempted to identify how gender differences affect employment opportunities and social inequalities, which has led to a growing body of literature. However, sufficient and valid conclusions are not yet available to identify the reasons for the gender pay gap (GPG). Building on key theoretical models to explain the wage gap, our research, based on a short survey, aimed to identify which factors could be related to the perception of GPG among employees of small- and medium-sized enterprises in five European countries. Moreover, we investigated the possible relationships between personal characteristics such as gender, age, job satisfaction, gender orientation (which is categorized as 'Negative Gender Orientation', i.e., sexist beliefs, and '’Positive Gender Orientation', i.e., perceived gender equality in society), and the GPG and tried to estimate a possible functional relationship between the perceived GPG and the decision-making style. The results revealed differences between personal characteristics and perceptions of the GPG; the findings were discussed in accordance with the present literature on the topic.
\end{abstract}

Keywords Gender pay gap · Discrimination · Workplace · Employment · Perception

\section{Introduction}

The principle of equal pay for women and men has been signed by the European Economic Community since the Treaty of Rome in 1957. The Treaty of Rome is, to all intents and purposes, the first European legislative act in favor of equal opportunities between genders (and it is also the constitutive act of the European Economic

Giulia Lausi

giulia.lausi@uniroma1.it

1 Department of Psychology, Sapienza University of Rome, Via dei Marsi, 78, 00185 Rome, Italy

2 Department of Dynamic and Clinical Psychology, Sapienza University of Rome, Rome, Italy 
Community itself - now the European Union). Article 119 introduced the principle of equal pay and remuneration between men and women workers for the same work and all other benefits. This principle was immediately implemented also by the European Court of Justice, which, even still, defines the need to provide equal pay to women and men who perform work of equal value (1975/117/CEE; Vitali 2009).

Despite the rules and laws issued by individual countries, the gender pay gap (GPG) problem, defined as "the difference between the average gross earnings per hour of men and women" (European Institute of Gender Equality - EIGE), persists. For instance, in the European Union, women's gross hourly earnings were on average $14.8 \%$ below those of men (Eurostat 2018), but there are many differences between Member States.

As highlighted by the European Commission in 2014, further instruments focusing on other factors (e.g., education, training, awareness raising) may be required since laws and sanctions do not seem to be adequate to face the GPG phenomenon and achieve effective gender equality. Over a few decades, interest in gender research has switched to empirical investigations to address the growing interest of public administrations in identifying how gender differences affect job opportunities (Bishu and Alkadry 2017) and social inequalities (Činčalová 2020). These studies are socially and economically relevant because of their implications when investigating access to these opportunities (Huffman and Cohen 2004; Smith 2002). Most studies on employment discrimination have focused on gender and race discrimination by selecting a discrimination area for research (e.g., the gender pay gap) in relation to career promotion.

A growing body of literature highlights the importance of the gender pay gap (GPG) by investigating its underlying factors and mechanisms (Blau and Kahn 2006; Rubery et al. 2005). Investigating the gender pay gap is an ongoing concern in the context of economic discrimination against women; although economic disparity between genders is now illegal, the gender pay gap globally persists (Eurostat 2019; Salverda et al. 2009).

\section{Background theories in explaining the GPG}

Several descriptive studies have used a traditional approach (i.e., economic) by addressing factors such as education, skills, social, and individual discrimination (Anderson et al. 2001; Blau and Khan 2003; Rubery et al. 2005). In contrast, substantially less attention has been given to the psychological factors of the GPG (e.g., decision-making and gender orientation, meant as the presence of stereotypes, both hostile and benevolent; Glick and Fiske 2001). Different theories and approaches consider socioeconomic issues to be a dominant feature to explain social factors and motivation under the GPG. For instance, the "human capital approach" (Lips 2013) has often been used as an argument that much of the GPG is due to men's and women's use of different career strategies and investments. Indeed, several studies have shown that individuals often do not perceive the existence of the GPG, even when it is supported by economic data (Jamali et al. 2008; Lange 2008). A second theory that attempts to explain the existence of the GPG is the "Family Obligation 
Explanation Theory", according to which one of the factors underlying inequalities is the responsibility of women to take care of household work, children, and family members. A significant gender pay gap is closely related to women's years of fertility and childcare. The "motherhood penalty" or "family gap" and its contribution to the GPG have been widely confirmed by microdata studies (Salverda et al. 2009). Childhood leads to a separation of work, leading to a further loss of specific human capital (Becker 1991; Corcoran 1977; Mincer and Ofek 1979; Mincer and Polachek 1974). In addition, mothers may receive lower returns due to an actual or perceived decrease in commitment or effort at work. The GPG is, therefore, the result of a situation in which care work and paid employment are mutually opposed (Becker 1985). Furthermore, "The Wage Compensation Explanation" assumes that women and men seek different characteristics in their work, and this results in a GPG: men choose the most challenging jobs, while women choose the most flexible hours and human contact in the workplace. The GPG would therefore not be an existing inequality but the result of different job choices (Filer 1985). Many other GPG explanations (Gaiaschi 2019) are linked to a difference in the structural, organizational and/or institutional characteristics of employment: horizontal segregation (i.e., gender distribution between sectors and occupations or vertical segregation in careers) (Blau and Kahn 1997; England 1992; Grimshaw and Rubery 2007), geographical variation in labor demand (Grimshaw and Rubery 2007) and organizational characteristics, such as the level of unionization and the size of the company (Olsen and Walby 2004).

Since the late ' $80 \mathrm{~s}$, however, sociological and psychological research has found a new explanation for inequalities in earned income through liberal egalitarian theories of distributive justice (Dworkin 1981; Cohen 1989; Le Grand 1991; Fleurbaey 1994; Boadway et al. 2002). More specifically, job segregation explanation theory states that women must choose lower-paid jobs and less advantageous positions than men. Gender segregation, according to this theory, is built into work hierarchies, supported by stereotypes and workplace relationships (Le Grand 1991); moreover, consistent with liberal egalitarian theories, income inequalities are the result of individual opportunities and choices. Therefore, society should redistribute resources to give people the opportunity to achieve their idea of a "good life" only through individual choice and ensuring fair access to resources (Loo 2016; Cappelen and Tungodden 2017). Behavioral economics research has shown that people, consistent with liberal egalitarian theories, seem to attribute inequalities to individual choices while rejecting the possibility that economic inequalities result from luck or access to resources (Konow 2001; Frohlich and Oppenheimer 2004; Oppenheimer 2012; Cappelen et al. 2014).

To date, very limited attention has been given to verify these assumptions, and the experimental data are rather controversial, highlighting the lack of general agreement: from a scientific point of view, none of these theories can by itself explain the GPG phenomenon, which is-as mentioned-due to a set of nonexhaustive factors. 


\section{The present study}

The gender pay gap persists as a problem in Europe (Eurostat 2018), and the implementation of social policies also depends on how the phenomenon is perceived within a determined culture. Psychological variables such as attitudes toward gender roles can influence the perception of the phenomena and, consequently, affect the implementation of social policies. Because of the limited attention given to the psychological factors underlying the GPG, such as attitudes toward gender roles and decision-making styles, research comparing different European countries could provide an accurate overview of the European situation. Therefore, Italy promoted a cross-national psychological study to investigate the perception of the GPG and its determinants among employees at small- and medium-sized enterprises in 5 EU countries (Austria, Bulgaria, Czech Republic, Greece, Italy); the project provides detailed results for the GPG in all participating countries, also considering unregistered forms of remuneration, such as bonus payments, project payments or seasonal payments.

For this reason, as part of the project, a survey was conducted based on a short questionnaire that aimed to identify the main factors linked to the perception of the GPG. The empirical research approach adopted for this study considered psychological and individual factors that are known to play a role in the perception of gender roles and, therefore, the perceptions of the GPG phenomenon.

It is known that individuals with a traditional gender role orientation tend to perceive the gender pay gap less than those with a more egalitarian gender role orientation (Duehr and Bono 2006). Additionally, perception of workplace and overall gender inequality could moderate the perception of the gender pay gap. Finally, gender concentration (i.e., organizations with more male or female individuals among their employees) may affect how the gender pay gap is perceived among employees.

Demographic information has a deep impact on how individuals balance their work life and personal life, likely influencing their perception of the gender pay gap. For instance, studies have reported that older people have more traditional views about the role of women in the workplace, that married people are less concerned about the gender pay gap than unmarried people and that highly educated individuals are more aware and critical of this issue than less educated people (Judge and Livingston 2008; Paul 2006). Moreover, social differences in how gender inequalities are addressed may also influence how social problems are approached within nations (Smith 2012).

Research Question 1 identify, using the aggregated data from the 5 countries, the possible relationships between personal characteristics and gender orientation and perceived gender equality in the workplace.

Research Question 2 identify, within the 5 countries, the presence of any differences in gender orientation and perceived gender equality in the workplace. 
A body of experimental literature has investigated cooperation using the dualprocess framework on decision-making (Evans 2008); the dual-process contains two types of cognitive processes: automatic (intuitive) and controlled (deliberative). A cooperative and participatory workplace promotes an egalitarian workplace; for instance, recently, Lotz (2015) showed that cooperation and intuition are related in an asymmetric context that allocates the gains from cooperation differently among a group. To the best of our knowledge, no studies investigate this relationship in the context of the gender pay gap.

Research Question 3 assess a possible functional relationship between the perceived self-reported GPG and the variables examined (e.g., decision-making, workplace equality, gender orientation).

Although research has been conducted on psychological aspects in perceived self-reported GPG, no single study has investigated this phenomenon in Europe; therefore, this paper aims to improve the comprehension of the phenomenon from a psychological perspective.

\section{Method}

\section{Participants}

Data were collected from October 2014 to November 2016 from five countries (Bulgaria, Austria, Greece, the Czech Republic, and Italy). A total of 1227 participants joined the research; of those, 696 were female, 502 were male, and 29 did not indicate gender. In detail, 33\% were Bulgarian, $4.6 \%$ were Austrian, $17 \%$ were Greek, $30.3 \%$ were Czech and $15.1 \%$ were Italian. A total of $55.9 \%$ were married or in a registered partnership, $8.8 \%$ were divorced or separated, $11.2 \%$ were widowed, and $21.1 \%$ were single. Twenty-three percent of participants were between 18 and 32 years old, $47.3 \%$ were between 33 and 47 years old, and the remaining $21.7 \%$ were between 48 and 72 years old (Table 1).

\section{Materials}

Since no questionnaires investigate the psychological perception of the Gender Pay Gap, a questionnaire was created for the research to collect the following information.

\section{Demographic and salary information.}

The first section was designed to collect information about gender, age, marital status, caregiving responsibility for children, and elderly or disabled relatives. The second section investigated data about the work and the organization, such as work position and contract type. 
Table 1 Sociodemographic and employment characteristics of the study sample

\begin{tabular}{ll}
\hline Sociodemographic and employment characteristics & $M(\mathrm{SD})$ or $\%(N)$ \\
\hline Age (years) & \\
$18-32$ & $23 \%(278)$ \\
$33-47$ & $47.3 \%(573)$ \\
$48-72$ & $29.8 \%(360)$ \\
Gender & \\
Women & $58.1(696)$ \\
Men & $41.9(502)$ \\
Present marital status & \\
Married or in a registered partnership & $55.9 \%(680)$ \\
Divorced or separated & $8.8 \%(107)$ \\
Cohabiting & $11.2 \%(136)$ \\
Widowed & $2.0 \%(24)$ \\
Single & $22.1 \%(269)$ \\
Do you have children? & \\
Yes & $65.9 \%(799)$ \\
No & $34.1 \%(413)$ \\
Do you take care of elderly and/or disabled relatives? & \\
Yes & $25.8 \%(305)$ \\
No & $74.2 \%(875)$ \\
Employment contract & \\
Part time & \\
Full time & $75.5 \%(923)$ \\
Employment relationship & $24.5 \%(300)$ \\
Permanent & \\
Tempod-Term & $83.3 \%(1016)$ \\
& $11.9 \%(145)$ \\
& $4.8 \%(59)$ \\
\hline
\end{tabular}

\section{Gender equality perception}

The third section of the questionnaire investigated some variables that are known to affect the perceived self-reported gender pay gap. This was investigated through a scale, named "perceived gender equality in the workplace", focused on the perception of equality in the workplace (e.g., "in your opinion, how much gender equality is there in your workplace"); a Likert scale was used; participants were asked to rate how strongly they agreed with each statement. Additionally, gender orientation was investigated through items referring to a positive role of women in society (e.g., "women should play a more active role in politics to diversify the range of policy competencies", positive gender orientation) and items that refer to a more traditional/stereotyped role of women (e.g., "women's place is at home, not in the office or the store", negative gender orientation). 


\section{Decision-making}

Finally, a scale for decision-making style (preference for intuition and deliberation-PID; Betsch 2004; Betsch and Kuntz 2008) distinguishing between a more intuitive and a more deliberative style was included in the questionnaire. Coherently with the project, the aim was to investigate the possible relationships between how individuals perceive the gender pay gap and their decision-making style. The PID scale measures a person's tendency to use a particular decisionmaking style (Betsch 2004). The scale is composed of two subscales, intuition, and deliberation, and shows good internal consistency. The first is a scale of preference for intuition when making decisions, and the second is a preference to rely on explicit knowledge and planning. The PID consists of 19 items that are presented as questions or statements. Survey respondents were assessed on a fivepoint Likert scale.

\section{Perceived self-reported gender pay gap}

To identify the presence of self-reported GPG perception, specific questions about perceived salary and fair salary were administered; the difference between these two data points was analyzed for any gaps between the two genders. Because of the self-report nature of the item, the potential for intrinsic bias should be considered. This method was chosen for two reasons: first, to reduce possible intrinsic bias by creating a third variable; and second, we assumed that if individual perceptions of the GPG exist, the perceived salary and the reported fair salary will follow this trend, showing a gender difference between men and women, whereas the differential should neutralize these differences.

\section{Statistical analysis}

A total of 1227 questionnaires were delivered to the five countries mentioned above: Bulgaria, Austria, Greece, the Czech Republic, and Italy. Statistical analysis was performed using SPSS software (version 25.0).

In this study, for an overview of the five European countries involved, the whole sample was first analyzed. Subsequently, analyses were conducted to compare the countries on variables that might predict the perception of the GPG: perceived gender equality in the workplace and gender orientation (positive or negative). Sociodemographic characteristics were investigated. ANOVA was performed to identify possible differences in the perceived self-reported GPG between age groups, gender, present marital status, and presence/absence of children. To identify whether our variables predicted perceived self-reported GPG, multiple regressions were conducted on the total sample and among the different countries to investigate associations between variables of perceived self-reported GPG and personal characteristics. 


\section{Results}

\section{Gender and age differences in job satisfaction, perceived gender equality in the workplace and gender orientation (positive or negative)}

ANOVA was conducted to compare the differences between females and males in negative gender orientation and positive gender orientation. Statistically significant results emerged for negative gender orientation $\left(F_{(1,1185)}=24.37, p<0.001\right)$ and positive gender orientation $\left(F_{(1,1185)}=44.42, p<0.001\right)$ between groups. Men showed higher average scores in negative gender orientation, while women showed higher average scores in a gender equal view of society. No significant differences were found between men and women in job satisfaction and gender equality in the workplace (Table 2).

Regarding the three age groups, there was a statistically significant difference in negative gender orientation $\left(F_{(2,1197)}=4.23, p<0.05\right)$, positive gender orientation $\left(F_{(2,1196)}=5.51, p<0.001\right)$ and perceived gender equality in the workplace $\left(F_{(2,1164)}=3.41, p<0.05\right)$. Post hoc comparison using the Tukey HSD revealed a statistically significant difference between the 18-32 age range and the others for negative gender orientation, with the $18-32$ age group $(M=2.07, \mathrm{SD}=0.97)$ showing a lower mean score than the other two groups $(33-47, M=2.27, \mathrm{SD}=0.99 ; 48-72$, $M=2.28, \mathrm{SD}=1.07)$, while the $18-32$ age range $(M=3.56, \mathrm{SD}=0.77)$ and $48-72$ age range $(M=3.77, \mathrm{SD}=0.84)$ differed in positive gender orientation, with the former group showing lower scores than the latter group, while no differences emerged between the 18-32 and 33-47 age groups and the 33-47 and 48-72 age groups. Last, there was a statistically significant difference in perceived gender equality in the workplace between the $18-32$ age range $(M=2.86, \mathrm{SD}=0.97)$ and 33-47 age group $(M=3.07, \mathrm{SD}=1.09)$. No significant difference among the three groups was evident in job satisfaction (Table 3).

\section{Marital status, presence or absence of children, and caregiving responsibility differences in job satisfaction, perceived gender equality in the workplace and gender orientation (positive or negative)}

There was a statistically significant difference among the five marital status groups in negative gender orientation $\left(F_{(4,1200)}=4.60, p<0.001\right)$. Post hoc comparisons using the Tukey HSD test indicated that the mean score for the married group

Table 2 Differences between men and women in job satisfaction, perceived gender equality in the workplace, and gender orientation (positive or negative)

\begin{tabular}{lll}
\hline & Female & Male \\
\hline Job satisfaction & $2.46(.78)$ & $2.44(.80)$ \\
Gender equality in the workplace & $2.96(1.08)$ & $3.07(1.04)$ \\
Positive gender orientation & $3.80(.78)^{*}$ & $3.48(.83)^{*}$ \\
Negative gender orientation & $2.10(.97)^{*}$ & $2.40(1.06)^{*}$ \\
\hline
\end{tabular}

$M(\mathrm{SD})$ 
Table 3 Differences between group ages in job satisfaction, perceived gender equality in the workplace, and gender orientation (positive or negative)

\begin{tabular}{llll}
\hline & $18-32$ & $33-47$ & $48-72$ \\
\hline Job satisfaction & $2.49(.79)$ & $2.43(.79)$ & $2.49(.80)$ \\
Gender equality in the workplace & $2.86(.97)^{*}$ & $3.07(1.08)^{*}$ & $2.98(1.09)$ \\
Positive gender orientation & $33.56(.77)^{*}$ & $3.66(.82)$ & $3.77(.84)^{*}$ \\
Negative gender orientation & $2.07(.97)^{*}$ & $2.27(.99)^{*}$ & $2.28(1.07)^{*}$ \\
\hline
\end{tabular}

$M(\mathrm{SD})$

in the negative gender orientation $(M=2.31, \mathrm{SD}=1.02)$ was statistically significant, unlike the single condition $(M=2.03, \mathrm{SD}=0.92)$. However, the other marital status groups did not significantly differ from the married and single groups, either in negative gender orientation or on the other scales (Table 4). There were also significant differences between the group with children and the group without children on negative gender orientation $\left(F_{(1,1199)}=22.65, p<0.001\right)$ and on positive gender orientation $\left(F_{(1,198)}=6.90, p<0.01\right)$. Post hoc comparisons using the Tukey HSD test indicated that the mean score for the presence of children group on "Positive Gender Orientation" $(M=3.71, \mathrm{SD}=0.82)$ was statistically significant, unlike for the absence of children condition $(M=3.58, \mathrm{SD}=0.80)$. Furthermore, for "Negative Gender Orientation", the presence of children group was statistically significant $(M=2.32, \mathrm{SD}=1.02)$, unlike the absence of children condition $(M=2.03, \mathrm{SD}=0.97)$. Parents had a higher mean score on both scales with respect to the childless group, while no difference was found in job satisfaction and gender equality in the workplace (Table 5). The results showed no significant differences in mean scores on any of the scales for people with caregiving responsibility for elderly or disabled relatives.

Table 4 Differences between present marital status in job satisfaction, perceived gender equality in the workplace, and gender orientation (positive or negative)

\begin{tabular}{llllll}
\hline & $\begin{array}{l}\text { Married/ } \\
\text { registered } \\
\text { partnership }\end{array}$ & Divorced/separated & Cohabiting & Widowed & Single \\
\hline Job satisfaction & $2.44(.78)$ & $2.42(.81)$ & $2.45(.79)$ & $2.41(.87)$ & $2.51(.80)$ \\
$\begin{array}{l}\text { Gender equality in the } \\
\quad \text { workplace }\end{array}$ & $3.02(1.07)$ & $3.11(1.10)$ & $3.15(1.10)$ & $2.64(1.24)$ & $2.84(.97)$ \\
$\begin{array}{l}\text { Positive gender orientation } \\
\text { Negative gender orienta- } \\
\text { tion }\end{array}$ & $3.71(.81)$ & $3.70(.85)$ & $3.66(.77)$ & $3.61(1.03)$ & $3.55(.81)$ \\
\hline
\end{tabular}

$M(\mathrm{SD})$ 
Table 5 Differences between presence or absence of children in job satisfaction, perceived gender equality in the workplace, and gender orientation (positive or negative)

\begin{tabular}{lll}
\hline & Presence of children & Absence of children \\
\hline Job satisfaction & $2.45(.78)$ & $2.46(.80)$ \\
Gender equality in the workplace & $3.04(1.09)$ & $2.93(1.01)$ \\
Positive gender orientation & $3.71(.82)^{*}$ & $3.58(.80)^{*}$ \\
Negative gender orientation & $2.32(1.02)^{*}$ & $2.03(.97)^{*}$ \\
\hline
\end{tabular}

$M(\mathrm{SD})$

\section{Differences among countries in perceived gender equality in the workplace and gender orientation (positive or negative)}

To investigate the possible differences among countries in gender orientation and in perceived gender equality in the workplace, an ANOVA was conducted, and the different countries were compared on all the target variables of the questionnaire. The results showed statistically significant differences among the countries in negative gender orientation $\left(F_{(4,1211)}=40.34, p<0.001\right)$, in positive gender orientation $\left(F_{(4,1210)}=27.31, p<0.001\right)$, and in perceived gender equality in the workplace $\left(F_{(4,1177)}=39.01, p<0.001\right)$. Post hoc comparison using the Tukey HSD revealed statistically significant differences in negative gender orientation between Austria $(M=1.51, \mathrm{SD}=0.78)$ and Bulgaria $(M=2.54, \mathrm{SD}=1.11)$, Austria and Greece $(M=2.11, \mathrm{SD}=0.77)$, Austria and the Czech Republic $(M=2.35$, $\mathrm{SD}=0.93)$, and Bulgaria and Italy $(M=1.59, \mathrm{SD}=0.89)$; differences were also found between Greece and all the other countries involved in the research and between the Czech Republic and Italy. For positive gender orientation, post hoc comparison revealed a difference only between the Czech Republic $(M=3.32$, $\mathrm{SD}=0.72)$ and every other country involved in the research: Austria $(M=3.87$, $\mathrm{SD}=0.73)$, Bulgaria $(M=3.82, \mathrm{SD}=0.89)$, Greece $(M=3.87, \mathrm{SD}=0.61)$, and Italy $(M=3.77, \mathrm{SD}=0.85)$. Finally, regarding perceived gender equality in the workplace, each group differs from the others, apart from the Czech Republic $(M=2.85, \mathrm{SD}=0.90)$ and Italy $(M=3.00, \mathrm{SD}=1.17)$; Greece showed a lower perceived gender equality in the workplace $(M=2.44, \mathrm{SD}=0.80)$, while Bulgaria $(M=3.35, \mathrm{SD}=1.11)$ and Austria $(M=3.85, \mathrm{SD}=0.99)$ showed higher scores (Table 6).

Table 6 Differences among countries in perceived gender equality in the workplace and gender orientation (positive or negative)

\begin{tabular}{llllll}
\hline & Austria & Bulgaria & Czech Republic & Greece & Italy \\
\hline $\begin{array}{l}\text { Gender equality in the work- } \\
\text { place }\end{array}$ & $3.85(.99)^{*}$ & $3.35(1.11)^{*}$ & $2.85(.90)$ & $2.44(.80)^{*}$ & $3.00(1.17)$ \\
Positive gender orientation & $3.87(.73)^{*}$ & $3.82(.89)^{*}$ & $3.32(.72)^{*}$ & $3.87(.61)^{*}$ & $3.77(.85)^{*}$ \\
Negative gender orientation & $1.51(0.78)^{*}$ & $2.54(1.11)^{*}$ & $2.35(.93)^{*}$ & $2.11(.77)^{*}$ & $1.59(.89)^{*}$ \\
\hline
\end{tabular}

$M$ (SD) 
Table 7 Stepwise regression

\begin{tabular}{llcl}
\hline & Beta & \multicolumn{1}{l}{$t$} & Sig \\
\hline (Constant) & & 10.676 & .000 \\
PID_deliberation & .244 & 9.705 & .000 \\
Negative gender orientation & -.197 & -7.042 & .000 \\
Gender & -.134 & -4.816 & .000 \\
Job satisfaction & .072 & 2.566 & .010 \\
\hline
\end{tabular}

Dependent variable: Self-reported Gender Pay Gap; Variable Excluded: Positive Gender Orientation, PID_Intuition

Table 8 Stepwise regression (Bulgaria)

\begin{tabular}{lccc}
\hline & Beta & $t$ & Sig \\
\hline (Constant) & & 2.634 & .009 \\
Positive gender orientation & .368 & 6.871 & .000 \\
Job satisfaction & -.174 & -3.253 & .001 \\
\hline
\end{tabular}

Dependent variable: Self-reported Gender Pay Gap; Variable Excluded: Negative Gender Orientation, PID_Intuition, PID_Deliberation, Gender

\section{Differences in reported monthly salary}

Overall, women reported earning a lower net monthly salary than men $\left(F_{(1,1098)}=9.758, p<0.01\right)$. There was also a statistically significant difference between men and women in fair perceived salary $\left(F_{(1,1072)}=10.296, p<0.001\right)$, while there was no statistically significant difference between men and women in the differential between fair perceived salary and current net monthly salary.

Based on the literature review, a stepwise regression analysis was conducted to identify whether perceived self-reported GPG could be predicted by any of the variables, including gender, job satisfaction, decision-making style (intuitive and deliberative), gender orientation (positive and negative), and perceived workplace equality; gender, job satisfaction, deliberative decision-making style and negative gender orientation were significant in predicting perceived self-reported GPG $\left(F_{(4,1148)}=44.32, p<0.001, R^{2}=0.13\right)$. Overall, these results suggest differences between men and women and between different age groups in perceived self-reported GPG, but these differences themselves are not the only variables predicting the different perceptions of this phenomenon (Table 7). Moreover, to detect differences among the five countries, the same stepwise regression analysis was conducted in each country. The results showed that in Austria and Italy, perceived self-reported GPG was not predicted by any of the variables included in the equation. Different results emerged from Bulgaria $\left(F_{(2,290)}=29.59\right.$, $p<0.001, R^{2}=0.17$; Table 8), where job satisfaction and positive gender orientation were found to be significant predictors of perceived self-reported GPG, from Greece, where only job satisfaction predicted perceived self-reported GPG $\left(F_{(1,193)}=22.92, p<0.001, R^{2}=0.10\right.$; Table 9) and the Czech Republic, where 
Table 9 Stepwise regression (Greece)

\begin{tabular}{llll}
\hline & Beta & $t$ & Sig \\
\hline (Constant) & & -1.453 & .148 \\
Job satisfaction & .326 & 4.787 & .000 \\
\hline
\end{tabular}

Dependent variable: Self-reported Gender Pay Gap; Variable Excluded: Negative Gender Orientation, Positive Gender Orientation, PID_Intuition, PID_Deliberation, Gender

deliberative decision-making style was the only predictor of perceived GPG $\left(F_{(1,356)}=3.97, p<0.05, R^{2}=0.01\right.$; Table 10$)$.

\section{Discussion}

There is a considerable disparity in the way countries have become aware of discrimination issues and, therefore, in the way they have addressed the fight against the gender pay gap, and the basic principles have been embraced very unevenly. The findings of this study contribute to the growing body of literature documenting the gender pay gap (Bishu and Alkadry 2017; Jamali et al. 2008; Rubery et al. 2005). The main strength of this research lies in having aggregated and split data from the five European Union countries; these data gave an overview, through a single questionnaire for all the countries, of the perceived gender pay gap situation.

Overall, women report a lower net monthly salary than men; moreover, their perception of what a fair salary might be is lower than that of men. Nevertheless, the difference between the perceived fair wage and the earned salary showed no difference between men and women, which means that even though men perceived their salary earned as higher, they still find it different from the perceived fair wage. It could be assumed that women's acceptance of a lower salary results from an estimation of their work value: if women perceive themselves as less professionally desirable, they will tend to accept a different salary and a lower work position than their male colleagues.

\section{Results from the five aggregated European countries}

Our first research goal was to investigate by using aggregated data whether, regardless of country, gender orientation and perceived gender equality in the workplace were significantly different based on specific demographic variables. We found that

Table 10 Stepwise regression (Czech Republic)

\begin{tabular}{llll}
\hline & Beta & $t$ & Sig \\
\hline (Constant) & & -1.340 & .181 \\
PID_deliberation & .105 & 1.992 & .047 \\
\hline
\end{tabular}

Dependent variable: Self-reported Gender Pay Gap; Variable Excluded: Negative Gender Orientation, Positive Gender Orientation, PID_Intuition, Gender, Job Satisfaction 
women tend to have a more equal view of society, while men tend to have a more stereotypical view of gender roles; different gender orientations may affect the perception of gender roles (e.g., whether women can work in politics or men can take care of their children, as in Kupers 2005), leading to different career choices, as happens in many Western countries, where women are overrepresented in health care roles but are underrepresented in leadership positions (Croft et al. 2015; Leopold et al. 2016). Moreover, the "glass ceiling" and the "glass escalator" phenomena tend to favor men and older people in reaching management positions. Particularly in organizational contexts, managerial positions are held by people with a negative gender orientation (Williams 2013; Davis 2019).

Furthermore, our results showed that a greater perception of couple and parental life could be a mediating factor in the perception of gender roles; this result could be interesting to explore in future research, including the gender of children among the variables.

\section{Results among the five European countries}

Second, we compared the different countries on the same variables (i.e., gender orientation, perceived gender equality in the workplace) to identify possible diversities. The five countries differ in gender orientation and perceived gender equality in the workplace: it can be assumed that different economic and social policies influence the population of the individual countries differently in their perception of gender differences. European countries have many differences in socioeconomic and social welfare policies, particularly regarding equality in employment. Recent data suggest that wage discrepancies remain stable across nations (Boll and Lagemann 2018); moreover, heterogeneity across countries was observed with respect to certain motivations and characteristics of men and women underlying the GPG. Middle and Eastern European countries show markedly lower levels of gaps, with some exceptions confirmed by our results where the Czech Republic and Bulgaria show higher gender inequality in the workplace. Low and moderate gaps were observed in the countries of Western and Southern Europe (e.g., Italy), respectively. According to our findings, Greece has the second-lowest level of perceived gender equality in the workplace, showing higher scores on the negative and positive gender orientations. These findings are consistent with Plantenga et al. (2009), who found that Italy and Greece seem to still be far from gender equality in the workplace: although Plantenga et al.'s (2009) study was conducted several years ago, this finding is still relevant, according to our research, as well as in Boll and Lagemann (2018) .

\section{Predictors of the gender pay gap}

Finally, a further interesting aspect is linked to the predictors of the perceived selfreported gender pay gap. In fact, when investigating which predictors were significant for the whole sample, the results were very different from those emerging from individual countries. Certainly, job satisfaction, which seems to be a predictor for the whole sample, including Bulgaria and Greece, could play an important role in 
the perception of pay differences; this result is also present in a study by Clark and Oswald (1996), but to the best of our knowledge, no similar recent studies focus on this topic. Given its importance, future research should investigate the commonalities between job satisfaction and perceptions of the GPG; research that considers the differences and commonalities between individual countries may allow the implementation of social policies at European and national levels.

These findings point to several directions for future research on GPG, as the variables influencing the gender pay gap are multiple and can affect the perception and the phenomenon itself. The fact that decision-making styles, although differing between age groups and genders, do not influence the perception of the GPG does not exclude, however, that they might influence how the GPG is experienced; therefore, studies on decision-making could be more oriented in this direction.

\section{Limitations and future directions}

Despite the novel contribution of this study, some of its limitations warrant discussion. For instance, different small- and medium-sized enterprises were contacted, but only a few of them agreed to circulate the questionnaire among employees despite guarantees of anonymity and confidentiality. This result reduced the potential representativeness of the sample, especially in some countries. It is important to remember that one of the main difficulties of this survey was the cultural approach to the pay gap and retribution. In certain cultures, the amount of salary is considered a private component of one's life, and consequently, some participants were not willing to respond to key items of the questionnaire. For these reasons, the number of respondents from Austria was extremely small, which meant that the five samples were too different in size to be deeply compared. Future research should investigate whether the underlying processes of the GPG are the same in other European countries; additionally, future studies could conduct a similar survey to see if the situation differs from the one presented in this paper due to years of different welfare policies.

\section{Conclusion}

The European Union has set itself the objective of promoting equal opportunities through the elimination of the gender pay gap. The Treaty on the Functioning of the European Union (TFEU) states in Article 157 that men and women as workers must receive equal pay for equal work or work of equal value. Indeed, the European Commission has adopted a "Strategic Commitment for Gender Equality 2016-2019", which reaffirms its commitment to continue to promote equality between men and women by fighting against female poverty (Official Journal of the European Union 2008).

Labor costs and, consequently, wages are important elements within the labor market. In fact, they reflect the relationship between the labor demand of companies and the labor supply of individuals (Eurostat 2019). From these premises, 
the underlying reasons for the gender pay gap can include different labor force participation levels, the incidence of part-time employment among women compared to men, and the different attitudes of public and private organizations toward career development and parental leave or care for elderly and/or disabled family members.

While the focus of the research is on the gender pay gap, the paper has presented more broadly interesting empirical insights into the perception of discrimination at work by female and male employees. The traditional approach for explaining the gender pay gap has mainly focused on the weaknesses of women compared to men. This approach, however, does not consider the fact that women, until a few years ago, did not have access to higher education levels and relevant professional experience and to careers or positions of power. Another aspect concerns, for example, the combination of a professional career and private life: the role of caring for the family, explained by the family obligation explanation theory (Salverda et al. 2009). Women, therefore, have always managed to combine domestic work, performed at home and without pay, with professional work, carried out elsewhere and paid. Moreover, this approach has neglected apparently less important factors that influence and could explain how the gender pay gap is perceived.

Although this study focuses on perceived gender pay gaps, the findings may have an impact on examining differences between gender orientation in males and females that could influence perceived equality in the workplace. The difference in negative gender orientation between males and females could be explained by looking at the role men have in the hierarchy of enterprises. Men, typically leading organizations or in relevant positions, might have a view of society that is more oriented toward benevolent sexism and a more stereotypical view of the role of women in society. This attitude is also reflected in personnel selection in relation to male and female roles, which leads to the perpetuation of stereotyped gender roles. Therefore, in the labor market, factors such as negative or positive gender orientation maintain or reduce gender differences.

Future studies could investigate whether the determinants of the GPG may differ across countries; this result could depend on the specific labor market dynamics in each country. Determinants within the human capital approach could be effective and rather stable across countries; however, psychological determinants also modulate the GPG, again in different ways among countries. The variability in the nature and effectiveness of determinants may suggest the implementation of country-specific and tailored countermeasures. The results presented in this work can be considered as suggestions for further studies in the European context.

Acknowledgements This research was part of "Zero Gender Pay Gap Project - Gender e-quality: Innovative tool and awareness raising on GPG". Project's leading body has been the Department of Psychology of Sapienza University of Rome and the partners have been: NACW (AT); 4 Elements (GR); Equanima (CZ); Gender Project for Bulgaria Foundation (BG); and Fondazione Risorsa Donna (IT).

Author contributions All authors contributed to the collection, analyses, and write-up of the manuscript and have given their consent for submission. All sources used have been duly referenced.

Funding The authors disclosed receipt of the following financial support for the research, authorship, and/or publication of this article: this research was supported by EC - DG Justice. 
Data availability The data for this paper are available upon request.

\section{Declarations}

Conflict of interest The authors declared no potential conflicts of interest with respect to the research, authorship, and/or publication of this article.

\section{References}

Anderson T, Forth J, Metcalf H, Kirby S (2001) The gender pay gap. Final Report to the Women and Equality Unit, Cabinet Office Women and Equality Unit, London. https://doi.org/10.1177/09500 17004040765

Becker GS (1985) Human capital, effort, and the sexual division of labour. J Labour Econ 3(1, Part 2):S33-S58. https://doi.org/10.1086/298075

Becker GS (1991) A treatise on the family, enl. Harvard University Press, Cambridge

Betsch C (2004) Prafrenz fuer intuition und deliberation. Inventar zur erfassung von affektund kognitionsbasiertem entscheiden [Preference for intuition and deliberation (PID): An inventory for assessing affect- and cognition-based decision-making]. Zeitschrift Fuer Differentielle Und Diagnostische Psychologie 25:179-197. https://doi.org/10.1024/0170-1789.25.4.179

Betsch C, Kuntz JJ (2008) Individual strategy preferences and decisional fit. J Behav Dec Making 21:532-555. https://doi.org/10.1002/bdm.600

Bishu SG, Alkadry MG (2017) A systematic review of the gender pay gap and factors that predict it. Adm Soc 49(1):65-104. https://doi.org/10.1177/0095399716636928

Blau FD, Kahn LM (1997) Swimming upstream: trends in the gender wage differential in the 1980s. J Labor Econ 15(11):1-42. https://doi.org/10.1086/209845

Blau FD, Kahn LM (2003) Understanding international differences in the gender pay gap. J Law Econ 21(1):106-144. https://doi.org/10.1086/344125

Blau FD, Kahn LM (2006) The US gender pay gap in the 1990s: slowing convergence. ILR Rev 60(1):45-66. https://doi.org/10.1177/001979390606000103

Boadway R, Marchand M, Pestieau P, del Mar Racionero M (2002) Optimal redistribution with heterogeneous preferences for leisure. J Public Econ Theory 4(4):475-498. https://doi.org/10.1111/10973923.00106

Boll C, Lagemann A (2018) Gender pay gap in EU countries based on SES (2014). Publ Office Eur Union 10:978935

Cappelen AW, Tungodden B (2017) Fairness and the proportionality principle. Soc Choice Welf 49(3):709-719. https://doi.org/10.1007/s00355-016-1016-6

Cappelen AW, Eichele T, Hugdahl K, Specht K, Sørensen EØ, Tungodden B (2014) Equity theory and fair inequality: a neuroeconomic study. Proc Natl Acad Sci 111(43):15368-15372. https://doi.org/ $10.1073 /$ pnas. 1414602111

Činčalová S (2020) Inequalities in social responsibility across Europe focused on work-life balance. Calitatea 21(174):142-146

Clark AE, Oswald AJ (1996) Satisfaction and comparison income. J Public Econ 61(3):359-381. https:// doi.org/10.1016/0047-2727(95)01564-7

Cohen GA (1989) On the currency of egalitarian justice. Ethics 99(4):906-944. https://doi.org/10.1086/ 293126

Corcoran ME (1977) Work experience, labor force withdrawals, and women's wages: empirical results using the 1976 panel of income dynamicse. In: Iloyd CB, Andrews ES, Gilroy CL (eds) Women in the labor market. Columbia University Press, New York

Croft A, Schmader T, Block K (2015) An underexamined inequality: cultural and psychological barriers to men's engagement with communal roles. Pers Soc Psychol Rev 19:343-370. https://doi.org/10. $1177 / 1088868314564789$

Davis SL (2019) Understanding and improving gender equity in conservation. J Am Inst Conserv 58(4):202-216. https://doi.org/10.1080/01971360.2019.1612723

Duehr E, Bono J (2006) Men, women, and managers: are stereotypes finally changing? Pers Psychol 59(4):815-846. https://doi.org/10.1111/j.1744-6570.2006.00055.x 
Dworkin R (1981) What is equality? Part 2: equality of resources 1. Philos Public Aff 10:283-345. https://doi.org/10.1017/S0266267100001930

England P (1992) Comparable worth: theories and evidence. Aldine de Gruyter, New York

Eurostat (2018) Gender pay gap statistics. https://ec.europa.eu/eurostat/statistics-explained/index.php/ Gender_pay_gap_statistics

Eurostat (2019) Retribuzioni e costo del lavoro, https://ec.europa.eu/eurostat/statistics-explained/index. php?title=Wages_and_labour_costs/it\&oldid=462404\#Differenziale_retributivo_di_genere

Evans JSBT (2008) Dual-processing accounts of reasoning, judgment, and social cognition. Annu Rev Psychol 59(1):255-278. https://doi.org/10.1146/annurev.psych.59.103006.093629

Filer RK (1985) Male-female wage differences: the importance of compensating differentials. ILR Rev 38(3):426-437. https://doi.org/10.1177/001979398503800309

Fleurbaey M (1994) On fair compensation. Theory Decis 36(3):277-307. https://doi.org/10.1007/BF010 79932

Frohlich N, Oppenheimer J (2004) Self-interest. In: The encyclopedia of public choice. Springer, Boston, pp 842-844. https://doi.org/10.1007/978-0-306-47828-4_185

Gaiaschi C (2019) Same job, different rewards: the gender pay gap among physicians in Italy. Gend Work Organ. https://doi.org/10.1111/gwao.12351

Glick P, Fiske ST (2001) An ambivalent alliance: hostile and benevolent sexism as complementary justifications for gender inequality. Am Psychol 56(2):109

Grimshaw D, Rubery J (2007) Undervaluing women's work. Equal Opportunities Commission, Manchester

Huffman ML, Cohen PN (2004) Occupational segregation and the gender gap in workplace authority: national versus local labour markets. In: Sociological forum, vol 19(1). Kluwer Academic Publishers-Plenum Publishers, pp 121-147. https://doi.org/10.1023/B:SOFO.0000019650.97510.de

Jamali D, Sidani Y, Kobeissi A (2008) The gender pay gap revisited: insights from a developing country context. Gend Manag 23(4):230-246. https://doi.org/10.1108/17542410810878059

Judge T, Livingston B (2008) Is the gap more than gender? A longitudinal analysis of gender, gender role orientation and earnings. J Appl Psychol 93(5):994-1012. https://doi.org/10.1037/0021-9010.93.5. 994

Konow J (2001) Fair and square: the four sides of distributive justice. J Econ Behav Organ 46(2):137164. https://doi.org/10.1016/S0167-2681(01)00194-9

Kupers TA (2005) Toxic masculinity as a barrier to mental health treatment in prison. J Clin Psychol 61(6):713-724. https://doi.org/10.1002/jclp.20105

Lange T (2008) Communist legacies, gender and the impact on job satisfaction in Central and Eastern Europe. Eur J Ind Relat 14:327-346. https://doi.org/10.1177/0959680108094138

Le Grand C (1991) Explaining the male-female wage gap: job segregation and solidarity wage bargaining in Sweden. Acta Sociologica 34(4):261-277. https://doi.org/10.1177/000169939103400402

Leopold TA, Ratcheva V, Zahidi S (2016) Gender parity and human capital (the global gender gap report 2016). World Economic Forum, Geneva

Lips HM (2013) The gender pay gap: challenging the rationalizations. Perceived equity, discrimination, and the limits of human capital models. Sex Roles 68(3-4):169-185. https://doi.org/10.1007/ s11199-012-0165-z

Loo C (2016) Environmental justice as a foundation for a process-based framework for adaptation and mitigation: a Commentary on Brooks. Ethics Policy Environ 19(2):145-149

Lotz S (2015) Spontaneous giving under structural inequality: intuition promotes cooperation in asymmetric social dilemmas. PLoS ONE 10(7):e0131562. https://doi.org/10.1371/journal.pone.0131562

Mincer J, Ofek H (1979) The distribution of lifetime labour force participation of married women: comment. J Polit Econ 87(1):197-201. https://doi.org/10.1086/260748

Mincer J, Polachek S (1974) Family investments in human capital: earnings of women. J Polit Econ 82(2, Part 2):S76-S108. https://doi.org/10.1086/260293

Official Journal of the European Union (2008) Consolidated versions of the Treaty on European Union and the Treaty on the Functioning of the European Union. https://eur-lex.europa.eu/legal-content/ EN/TXT/PDF/?uri=OJ:C:2008:215:FULL\&from=IT

Olsen W, Walby S (2004) Modelling gender pay gaps, vol 17. Equal Opportunities Commission, Manchester

Oppenheimer J (2012) Principles of politics: a rational choice theory guide to politics and social justice. Cambridge University Press, Cambridge. https://doi.org/10.1017/CBO9781139053334 
Paul M (2006) A cross-section analysis of the fairness-of-pay perception of UK employees. J Socio-Econ 35(2):243-267. https://doi.org/10.1016/j.socec.2005.11.005

Plantenga J, Remery C, Figueiredo H, Smith M (2009) Towards a European Union gender equality index. J Eur Soc Policy 19(1):19-33. https://doi.org/10.1177/0958928708098521

Rubery J, Grimshaw D, Figueiredo H (2005) How to close the gender pay gap in Europe: towards the gender mainstreaming of pay policy. Ind Relat J 36(3):184-213. https://doi.org/10.1111/j.14682338.2005.00353.x

Salverda W, Nolan B, Smeeding TM (eds) (2009) The Oxford handbook of economic inequality. Oxford University Press, Oxford

Smith RA (2002) Race, gender, and authority in the workplace: theory and research. Ann Rev Sociol 28(1):509-542. https://doi.org/10.1146/annurev.soc.28.110601.141048

Smith M (2012) Social regulation of the gender pay gap in the EU. Eur J Ind Relat 18(4):365-380. https:// doi.org/10.1177/0959680112465931

Trattato di Roma (1957) https://eur-lex.europa.eu/legal-content/IT/TXT/?uri=LEGISSUM:xy0023

Vitali F (2009) I luoghi della partecipazione. Una ricerca su donne, lavoro e politica. FrancoAngeli.

Williams CL (2013) The glass escalator, revisited: gender inequality in neoliberal times, SWS feminist lecturer. Gender Soc 27(5):609-629. https://doi.org/10.1177/0891243213490232 